RESOURCE ALLOCATION

\title{
Autonomy, consent, and limiting healthcare costs
}

\author{
M A Graber, J F Tansey
}

J Med Ethics 2005;31:424-426. doi: 10.1136/jme.2003.003574

While protection of autonomy is crucial to the practice of medicine, there is the persistent risk of a disconnect between the notion of self-determination and the need for a socially responsible medical system. An example of unbridled autonomy is the preferential use of costly medications without an appreciation of the impact of using these more expensive drugs on the resource pool of others. In the USA, costly medications of questionable incremental benefit are frequently prescribed with the complicity of both doctors and patients. Limiting self-determination in medication choices via an appreciation of the principle of justice reaches a better moral balance, while at the same time acknowledging the goals of doing good and avoiding harm in patient care.

See end of article for authors' affiliations

Correspondence to: $\operatorname{Dr} M A$ Graber,

Department of Family Medicine, Pomerantz Family Pavilion, University of lowa, 200 Hawkins Drive, lowa City, IA 52246; mark-graber@ viowa.edu

Received 10February 2003 In revised form

16 March 2004

Accepted for publication

14 July 2004 relevant to their own situation, and be able to weigh the possible choices in the light of their own value system. ${ }^{\text {? }}$

\section{THE MEDIA AND CONSENT}

Consent does not exist in a vacuum; information garnered from the media, friends, etc. also enter into a patient's decision making process. Because of this, there is often a failure in the informed consent process at the level of the patient's understanding the facts relevant to the medical decision at hand. In fact, the information that patients have is often purposefully incorrect. A compelling example of this is the information provided in direct to consumer advertising both in the media and on the world wide web. Such marketing strategies frequently contain misleading information and minimise any mention of side effects and risks. ${ }^{10-16}$ As a result of advertising, patients have an unrealistic view of newer medications and nearly half of the patients believe that advertised drugs are "completely safe $^{\prime \prime}{ }^{17-19}$ This leads to patients unknowingly taking unwanted risks. This is especially true with newer brand name medications for which data collection is still actively underway even after Food and Drug Administration (FDA) approval. "Black box" warnings are often issued years after a drug is introduced, and there is a $20 \%$ chance that a new drug will either be withdrawn from the market or receive a "black box" warning (a warning about potentially severe side effects or death) from the FDA within 25 years of the drug's release. ${ }^{20}$ Patients need to be made aware of what they do not know about advertised drugs before making a choice. Since patients generally like to minimise risk, they appropriately rely on their care providers for this information before proceeding to making a medical choice.

Unfortunately, providers may also be uneducated about medication indications, risks and benefits, or, even more frighteningly, manipulated by marketing strategies themselves. Healthcare providers often prescribe new drugs based on faulty information and persuasion provided by the pharmaceutical industry. ${ }^{21-26}$ Given the faulty information provided by pharmaceutical industry representatives, doctors who do not limit marketing intrusions are at great danger of impeding the informed consent process. Thus, a mechanism is needed to facilitate a discussion between the doctor and patient to optimise the process of consent.

Informed consent, even if it is a highly prized and protected institution, does not exist in a void. Appropriately, issues of justice come into play. The members of the therapeutic relationship-doctor and patient-must not fail to 
consider the complementary and competing moral claims outside of maximising a single person's medical health. Yet, as noted above, the participants in informed consent are often misinformed about risk and unaware of the social impact of their medical options. We are particularly interested in drawing attention to the larger economic impact of choosing a more expensive brand name medication over a less expensive but equally efficacious option. It is to be expected that economic consequences seem abstract when there are no out-of-pocket costs or a limited co-pay at the time of the visit. The unfortunate result of this, plus the misinformation as discussed earlier, is that patients use more prescription medications and prefer more expensive drugs over less expensive, equally effective, options. ${ }^{27}{ }^{28}$ As outlays for drugs rise, insurance rates climb. Individuals who must pay for part of their insurance have less disposable income or may not be able to afford health insurance. Likewise, as costs rise, fewer businesses provide insurance or diminish the quality of coverage for their employees. Failing to consider the principle of justice within the therapeutic relationship compromises the medical health of others, ${ }^{29}$ and impedes the informed consent process since inadequate information is available with which to make a fully autonomous choice.

\section{RECONNECTING INFORMED CONSENT WITH SOCIAL RESPONSIBILITY}

Disclosing the societal impact of certain medical choices, such as choosing a brand name medication, adds a tier of responsibility that is not typically assigned to the doctor. We suggest that doctors must initiate disclosure and dialogue about social justice as part of optimising the informed consent process. A patient, influenced by marketing and with limited expertise in interpreting the evidence based nature (or lack thereof) of advertising claims, requires doctors to provide information about the true costs, both financial and social, of the medication being considered in addition to the more typical medical risks and benefits of the option. Failure to disclose such information as morally relevant to the choice of medical options constitutes an impediment to patient decision making capacity - a disrespect of patient autonomy. Failure to disclose also represents a failure of doctors' obligations to society as participants in judicious resource allocation-a component of the principle of justice.

\section{RESOLUTION}

Two problems have been stated: the lack of information on the part of doctors and patients and the lack of a consideration of societal justice in medication choices.

A necessary part of this solution is that doctors educate themselves about the costs and adverse affects of medication. Additionally, doctors and healthcare professionals need to participate in discussions of social policy regarding pharmaceutical advertising. Doctors must work to establish clear professional standards to aggressively limit interactions with pharmaceutical representatives. It can be argued that pharmaceutical companies have no moral responsibility to provide objective information since they are in the commercial sector and not part of the doctor-patient relationship. This may be true. However, this transfers the onus of moral responsibility to the doctor and patient. When this misinformation is translated into action by doctors and patients, it has implications for justice, patient safety, and for the informed consent process as noted above. Providers might also refuse to prescribe expensive trade medications when other equally or more efficacious options are available, even when it has an impact on their patient base. All of these options, while unpopular in some circles, will help to optimise the integrity of doctor and patient autonomy in medical decision making.
A second part of the solution is a discussion of the impact of medication choices on patient risk and on the rest of society. It may be that such disclosure could be standardised in a way that opens dialogue and shifts the doctor's responsibility for undetermined risk and resource allocation to shared doctor and patient responsibility. Perhaps one way to do this would be to create a formal document to concretise the process of informed consent.

\section{I, as the patient, am requesting that my provider prescribe} drug for me. I understand there are less expensive medications that are also effective. I understand that by requesting this more expensive medication I am increasing healthcare costs to others, increasing the cost of insurance, using resources that could be used elsewhere in the healthcare system and may be taking an additional risk to my health as all of the side effects of new drugs may be not known. The reason that I am asking for this medication is I believe that the benefit to me outweighs the potential risks and resultant harms to others.

\section{CONCLUSION}

While there is no doubt that the principle of justice is a difficult one to acknowledge in a society that privileges the freedoms of an individual, it is important to acknowledge that optimising autonomy necessarily involves the acquisition and processing of adequate information with which to make a decision. In the therapeutic relationship, both doctors and patients must be encouraged to consider social responsibility as absolutely necessary information to the process of informed consent. Explicit acknowledgement of the impact of medical decisions on the society in which one lives must not be avoided. Professional standards, medical policies and social regulations, and the very dialogue that happens in the therapeutic space are all in need of refinement to support a more rigorous informed consent process.

\section{Authors' affiliations}

M A Graber, Departments of Family Medicine and Emergency Medicine, University of lowa Carver College of Medicine, lowa City, IA, USA J F Tansey, Department of Psychiatry and Program in Biomedical Ethics and Medical Humanities, University of lowa Carver College of Medicine, lowa City, IA, USA

\section{REFERENCES}

1 National Institute for Health Care Management Foundation, Prescription Drug Expenditures in 2000: The Upward Trend Continues, May 2001. Available at www. nihcm.org (accessed 12 August 2002).

2 The National Institute of Health Care Management Research and Educational Foundation, Prescription Drugs and Mass Media Advertising, 2000, November 2001. Available at www.nihcm.org (accessed 8 July 2002).

3 Bell RA, Wilkes MS, Kravitz RL. Advertisement-induced prescription drug requests: patients' anticipated reactions to a physician who refuses. I Fam Pract 1999;48:446-52.

4 Spurgeon $\mathbf{D}$. Doctors feel the pressure from direct to consumer advertising. Western J Med 2000;172:60.

5 Holmer AF. Direct-to-consumer prescription drug advertising builds bridges between patients and physicians. JAMA 1999;281:380-2.

6 Siegel D, Lopez J. Trends in antihypertensive drug use in the United States: do the JNC V recommendations affect prescribing? JAMA 1997;278:1745-8.

7 Mintzes B, Barer ML, Kravitz RL, et al. Influence of direct to consumer pharmaceutical advertising and patients' requests on prescribing decisions: two site cross sectional survey. BMJ 2002;324:278-9.

8 Beauchamp T, Childress J. Principles of Biomedical Ethics, 5th edn. Oxford: Oxford University Press 2001:79-80.

9 Grisso T, Appelbaum P. Assessing Competence to Consent to Treatment: A Guide for Physicians and Other Health Professionals. Oxford: Oxford University Press, 1998:31-60.

10 Bell RA, Wilkes MS, Kravitz RL. The educational value of consumer-targeted prescription drug print advertising. J Fam Pract 2000;49:1092-8.

11 Kessler DA. Addressing the problem of misleading advertising. Ann Intern Med 1992;116:950-1. 
12 Hollon MF. Direct-to-consumer marketing of prescription drugs: creating consumer demand. JAMA 1999;281:382-4.

13 Wade VA, Mansfield PR, McDonald PJ. Drug companies' evidence to justify advertising. Lancet 1989;2:1261-4.

14 Drug advertising: is this good medicine. Consumer Rep June 1996;61:62-3.

15 Woloshin S, Schwartz LM, Tremmel J, et al. Direct-to-consumer advertisements for prescription drugs: what are Americans being sold? Lancet 2001;358:1141-6.

16 Graber MA. Weckmann M. Pharmaceutical company internet sites as sources of information about antidepressant medications. CNS Drugs 2002;16:419-23.

17 Bell RA, Kravitz RL, Wilkes MS. Direct-to-consumer prescription drug advertising and the public. J Gen Intern Med 1999;14:651-7.

18 US Food and Drug Administration, FDA Consumer, 2002; 36 Magazine. Available at www.fda.gov/fdac/features/2002/chrtWithdrawals.html (accessed 14 September 2002)

19 Wood AJJ. The safety of new medicines: the importance of asking the right questions. JAMA 1999:28:1753.

20 Lasser KE, Allen PD, Woolhandler SJ, et al. Timing of new black box warnings and withdrawals for prescription medications. JAMA 2002;287:2215-20.

21 Miller LG, Blum A. Physician awareness of prescription drug costs: a missing element of drug advertising and promotion. J Fam Pract 1993;36:33-6.
22 Hoffman J, Barefield FA, Ramamurthy S. A survey of physician knowledge of drug costs. J Pain Symptom Manage 1995;10:432-5.

23 Safavi KT, Hayward RA. Choosing between apples and apples: physicians' choices of prescription drugs that have similar side effects and efficacies. J Gen Int Med 1992;7:32-7.

24 Stryer D, Bero LA. Characteristics of materials distributed by drug companies: an evaluation of appropriateness. J Gen Intern Med 1996;11:575-83.

25 Ziegler MG, Lew $P$, Singer $B C$. The accuracy of drug information from pharmaceutical sales representatives. JAMA 1995;273:1296-8.

26 Beevers DG, Ferner RE. Why are thiazide diuretics declining in popularity? J Human Hypertens $2001 ; 15: 287-9$.

27 Danzon P, Pauly Mark V. From hospital to drugstore: insurance and the shift to outpatient care. LDI Issue Brief, Leonard Davis Institute of Health Economics $2001 ; 7$.

28 Schwartz MP, Wagner PJ. Which medicines do our patients want from us? J Fam Pract 2000;49:339-41.

29 American College of Physicians/American Society of Internal Medicine Position Paper. No Health Insurance? It is Enough to Make You Sick- Scientific Research Linking the Lack of Health Coverage to Poor Health, 2000. Available at http://www.acponline.org/uninsured/lack-contents.htm (accessed 9 February 2003). 